\title{
Collaborative decision-making and promoting treatment adherence in pediatric chronic illness
}

This article was published in the following Dove Press journal:

Patient Intelligence

25 March 2010

Number of times this article has been viewed

\section{Dennis Drotar \\ Peggy Crawford \\ Margaret Bonner \\ Cincinnati Children's Hospital Medical Center, Cincinnati, Ohio, USA}

\begin{abstract}
Collaborative or shared decision-making between health care providers and families can facilitate treatment adherence, health outcomes, and satisfaction with care in the management of pediatric chronic illness, but raises special challenges. Barriers such as authoritarian models of medical care as well as absence of time and opportunity for dialogue limit collaborative decision making and can disrupt treatment adherence. However, models of provider-family communication that emphasize communication and shared goal-setting inform an anticipatory guidance model of collaborative decision-making that can enhance treatment adherence. Salient challenges and strategies involved in implementing collaborative decision-making in pediatric chronic illness care are described. Research is needed to: 1) describe the communication and decision-making process in the management of pediatric chronic illness; and 2) evaluate the impact of interventions that enhance collaborative decision-making on provider-family communication, illness management, and treatment adherence.
\end{abstract}

Keywords: collaborative decision-making, shared decision-making, treatment adherence, pediatric chronic illness

\section{Introduction}

Nonadherence to medical treatment in pediatric chronic illness has been identified as a frequent (rates of 50 or greater) and important problem that has a significant negative impact on symptom control, complications, and long-term health outcomes. ${ }^{1-6}$ The high prevalence and impact of nonadherence necessitate development of adherence promotion in chronic illness care. Positive provider-patient communication and treatment alliance are very important in adherence promotion. ${ }^{7-9}$ Collaborative (or shared) decision-making between health care provider and patient in medical treatment ${ }^{10,11}$ may promote treatment adherence, satisfaction with medical care, and positive health outcomes. ${ }^{12-14}$

The overwhelming majority of research and clinical observation concerning collaborative decision-making has focused on the medical treatment of adults and/or on discrete decisions such as whether to participate in medical screening tests, vaccination, or surgery as opposed to decisions related to chronic illness management. ${ }^{11-14}$ However, healthcare providers, parents, and children with pediatric chronic illness also engage in a series of important decisions concerning the life-long management of complex and burdensome medical treatments. Communication and collaborative decisionmaking among healthcare providers, parents, and children raise special challenges for pediatric chronic illness management. Although parents have the primary responsibility and authority to make healthcare decisions for their children in collaboration
Correspondence: Dennis Drotar 3333 Burnet Avenue, MLC 7039, Cincinnati, OH 45229-3039, USA Tel +l 5l3-636-3936 Email dennis.drotar@cchmc.org
Patient Intelligence 2010:2 I-7

(c) 2010 Drotar et al, publisher and licensee Dove Medical Press Ltd. This is an Open Access article which permits unrestricted noncommercial use, provided the original work is properly cited. 
with the child's physician, child and adolescent participation in treatment-related decisions can also facilitate effective management of their chronic conditions. ${ }^{15,16}$ The importance of collaborative decision-making in pediatric chronic illness management challenges health care providers to develop a greater understanding of this process and its impact on clinical care and health outcomes. A number of articles have focused on shared decision-making, collaborative management, and patient provider communication with adults with chronic illness. ${ }^{12-14}$ However, to our knowledge, none have focused on pediatric chronic illness management. To address this unmet need, this article describes the potential role of collaborative decision-making in the management of pediatric chronic illness and relevance to adherence promotion and implications for clinical practice and research.

\section{Nature of collaborative decisions}

As shown in Figure 1, the treatment of pediatric chronic illness involves a series of decisions for health care providers, patients, and parents that are made over the course of the child's illness. The first set of decisions involves the selection of a treatment regimen following the diagnosis of a chronic condition. Prescribed treatment regimens may involve one or more medications that are taken regularly (once or more a day), diet, or nutritional recommendations, as well as treatment of acute symptoms. ${ }^{3}$ Treatment plans may be individualized based on illness severity, emergent symptoms, or comorbid conditions. Moreover, initial treatment regimens may be modified in response to feedback from the parent and/or child concerning treatment efficacy and burden of treatment. Over the course of the child's illness, salient illness-related events such as deterioration in the child's health status or development of complications may also necessitate changes in prescribed treatment that are initiated by providers but discussed with parents and children.

Providers' decisions about potential changes in treatment plans can be informed by information from parents and children about the frequency and impact of symptoms, burdens associated with medical treatment, and the difficulties encountered in treatment adherence. Apart from recommended treatments, children, families, and health care providers may also discuss other clinically relevant decisions such as how best to fit complex treatments into family routines and how to allocate child and parental roles and responsibilities for chronic illness management. Although the lion's share of decision-making concerning the day-to-day management of chronic conditions is done by parents and children, providers may also be involved in these decisions, especially if families request their advice.

\section{Traditional communication models and their consequences for compliance}

The complex series of decisions in pediatric chronic illness management place significant demands on provider-family communication. Prevalent models of chronic illness care and time constraints in follow-up visits may limit the quality and quantity of dialogue and emotional support that are needed to promote effective communication and collaborative decision-making. ${ }^{17,18}$ For example, the traditional authoritarian or adherence/compliance model of care emphasizes the provider's role in prescribing treatment and the parent and child's role in following recommendations. ${ }^{17,18}$ This model is generally reinforced in the training of providers and also fits

\begin{tabular}{|c|c|c|c|}
\hline Decision-makers & Health care providers & $\begin{array}{l}\text { Health care provider, parent, } \\
\text { and patient }\end{array}$ & $\begin{array}{l}\text { Health care provider, } \\
\text { parent, and patient }\end{array}$ \\
\hline Types of decision & $\begin{array}{l}\text { Initial decision about what treatment } \\
\text { to recommend and how it should } \\
\text { be administered: } \\
\text { - Daily medications } \\
\text { - Nutritional treatment } \\
\text { - Preventive treatments } \\
\text { - Management of acute symptoms }\end{array}$ & $\begin{array}{l}\text { Decisions about how, when, and where } \\
\text { to administer treatments,allocation } \\
\text { of parent/child responsibility } \\
\text { for treatment }\end{array}$ & $\begin{array}{l}\text { - Decisions about } \\
\text { stopping and starting } \\
\text { medications } \\
\text { - Changing } \\
\text { medications } \\
\text { - Instituting } \\
\text { complementary } \\
\text { treatment }\end{array}$ \\
\hline & $\uparrow$ & $\uparrow$ & $\uparrow$ \\
\hline
\end{tabular}

Figure I Decision-making in pediatric chronic illness management. 
within the constraints of pediatric chronic illness followup visits that offer limited time for provider-family dialogue and/or decision-making. Based on information from a recent chart review in our institution, the average time for chronic illness follow-up visits is 20-30 minutes.

However, a growing body of empirical evidence has underscored the limitations of the authoritarian familyprovider relationship described above for pediatric chronic illness management. ${ }^{7,19}$ Taken together, empirical evidence underscores a mismatch between the level of provider-family communication and collaborative decision-making that may be necessary to develop and sustain treatment adherence versus what is typically provided within pediatric chronic illness care. ${ }^{719}$ For example, some adolescents with chronic conditions perceive their communications with their physicians as barriers to their treatment adherence (eg, "I have trouble understanding what the doctor tells me to do for my regimen; doctors are too busy to talk with me about my illness and regimen"). ${ }^{20}$ Loonen et $\mathrm{al}^{21}$ identified discrepancies in specific areas of chronic illness management that were ranked as important to adolescents with inflammatory bowel disease compared with those identified by their physicians. In this study, noncollaborative physician behavior, such as dictating how self-care should be carried out and ignoring opinions, related to nonadherence among adolescents with Type 1 diabetes. ${ }^{22}$ Clark et $a 1^{23}$ found that physicians' collaborative review of short-term treatment goals was associated with fewer office visits for pediatric asthma.

Taken together, these findings suggest that limited collaborative decision-making may undermine treatment adherence while greater collaborative decision-making may enhance it. What processes underly this effect? Without sufficient opportunity for dialogue concerning chronic illness treatment, families may be more likely to make independent management decisions, including decisions to limit or change treatment, rather than collaborate with their providers. Medical treatments for pediatric chronic illness raise many concerns (eg, side effects, lack of efficacy, and burden) that can lead children and parents to question various aspects of their medical treatment. The high rates of nonadherence to prescribed medical treatment indicate that management of pediatric chronic illness is more burdensome and difficult than many health providers assume. ${ }^{1-6,24} \mathrm{~A}$ substantial body of evidence also indicates that many children and adolescents with chronic illness and their parents are active decision-makers whose motivations, decisions, and capacity to follow recommended medical treatment depend on the degree to which they understand and accept the purpose of treatment. ${ }^{25-29}$ Parents' and children's beliefs about treatment efficacy versus burden of chronic illness treatment can influence their decisions about whether to sustain medical treatment. ${ }^{25-29}$ For example, children and parents are more likely to act on advice from providers to initiate or sustain a recommended treatment if they understand its purpose, believe in its potential efficacy, and that the barriers or costs associated with the treatment are less than the potential benefits. ${ }^{25-29}$ On the other hand, children, adolescents, and parents are more likely to decide to limit, omit, or choose an alternative treatment if they do not believe the treatment is effective, if they experience significant barriers to taking it, or if they believe that the side effects of treatments are problematic. However, such decisions are not typically shared with providers unless they ask about them.

Limited family-provider communication regarding treatment-related decisions may also make it very difficult for providers to respond effectively to changes in the child's condition, developmental stage, and family life. Given inevitable developmental, illness-related, and family changes, it is not surprising that parents and children may revisit medication-related decisions over the course of the child's treatment. Family routines may also change as a function of parental and child work schedules, activities, or life stressors, and disrupt treatment adherence. Children and adolescents tend to focus on here-and-now aspects of treatment because they affect their schedule, activities, appearance, and physical abilities, while parents are more likely to focus on both current and future impact. For example, it is not uncommon for adolescents to question the need for and benefits of medical treatment for their chronic illness because their prescribed treatments are difficult to reconcile with their valued social activities. $^{30}$

Children and parents may decide to change doses, omit, or substitute medications (eg, taking reliever medications as a substitute for daily controller medications for asthma) to reduce side effects or use complementary treatments. ${ }^{28-32}$ Such treatment-related decisions that are not shared with providers can result in problematic consequences, such as limiting the efficacy of treatment ${ }^{1}$ and inaccurate medical decisions to increase the dose of medications.

Over and beyond the potential consequences on treatment adherence and child health, noncollaborative decisionmaking may also limit the quality of the physician-child and/or physician-parent relationship. ${ }^{7,33}$ If and when providers eventually discover unilateral parental and/or child decisions to omit or take a different dose of medication, 
it may be very difficult for them to react dispassionately. Provider reactions can include frustration, anger, and mistrust (eg, "How can I help you if I don't know what is going on with your medication?"). In response to such reactions, patients and parents may feel blamed, which may result in a vicious cycle of decreased trust, communication, and collaboration with providers.

\section{Developmental issues in collaborative decision-making}

Developmental issues in collaborative decision-making are very important to consider because of age-related shifts in responsibilities and decisions related to chronic illness. ${ }^{15,16,34}$ For example, parents speak on behalf of younger (infant and preschool age) children when interacting with providers concerning decisions concerning chronic illness management. However, as children advance in their cognitive development, emotional autonomy, and interest in participating in management, many parents begin to involve them in decisions about day-to-day illness management or even decision about medical treatment. ${ }^{15,16,35}$ However, the nature of children's involvement in these decisions is highly variable across different families and not well documented in research.

When children reach adolescence their normative strivings for independence usually stimulate their interest and preference to be increasingly involved in decisions concerning their chronic illness care as well as in communication with their physicians. ${ }^{36,37}$ Moreover, in some instances, nonadherence to treatment may reflect refusal to agree with or accept the decisions concerning medical treatment by parents and providers. ${ }^{38}$

The transition from adolescence to adulthood in chronic illness care raises unique issues related to collaborative decision-making. ${ }^{39}$ Young adult patients need to attain the ability to engage in independent collaborative decision-making with their physicians that reflects their transition to adultoriented medical care. However, the developmental readiness of young adults to participate as active, independent collaborators, and their parents' capacities to support their children's independent adult roles in illness management varies widely. For this reason, young adults, parents, and providers may need additional support and structure to help them accomplish these difficult tasks. To this end, at some centers, specialized programs have been developed in order to facilitate the transition to adult care including patients' independent roles in collaborative decision-making with their physicians. ${ }^{40,41}$

\section{Promoting provider parent-child communication and decision- making in pediatric chronic illness}

Can collaborative decision-making among providers, parents, and children in the management of pediatric chronic illness be improved? Our answer is yes, but not without changing traditional provider-family communication patterns to enhance collaborative decision-making. Several different models such as: concordance, ${ }^{42-44}$ the five $\mathrm{As}^{45}$ and self-management ${ }^{46}$ provide alternatives to an authoritarian model of chronic illness care. Each of these emphasize communication and collaboration between patients (families) and providers. For example, the concordance model emphasizes the alliance between physician and patient, acknowledgement of patient/family expertise in managing health, and agreement between patient and providers about prescribed treatment. ${ }^{42-44}$ The five $\mathrm{As}^{45}$ model emphasizes five key components of chronic illness management: 1) assess, including assessment of beliefs, behaviors, and knowledge; 2) advise, defined as provision of information about health risks and benefits of change; 3) agree, comprising setting collaborative goals based on patient interests and confidence; 4) assist, ie, provide support for chronic illness model; and 5) arrange and develop a specific plan for followup visits. Finally, Lorig and Holman's ${ }^{46}$ self-management education model emphasizes three primary self-management tasks: medical management, role management, and emotional management, and six selfmanagement skills ie, problem solving, decision-making, resource utilization, formation of a patient-provider partnership, action planning, and self-tailoring.

The principles of each of these models can be applied to pediatric chronic illness management but need to be adapted to emphasize communication and collaborative decisionmaking with parents and children. To address this need, Pai and Drotar ${ }^{47}$ have proposed an anticipatory guidance model of collaborative adherence promotion in pediatric cancer that is applicable to other pediatric chronic conditions. Implementing a collaborative decision-making approach within an anticipatory guidance framework has the advantage of promoting teamwork and giving parents and children greater opportunity to participate in their treatment-related decisions. Key elements of this approach include providing family education concerning the importance of treatment adherence for the child's health outcomes, developing a plan to monitor treatment adherence that includes the child, parent, and physicians, encouraging the child and family to use basic skills in adherence promotion (eg, making specific plans for completion of treatment and who will 
be responsible for them), encouraging the development of family routines and reminders to enhance and emphasizing the importance of family and social support. This model focuses on collaborative decision-making to enhance adherence (eg, simplifying medication regimens in response to feedback from families and directly addressing medication side effects in discussions with child and parents). Ongoing monitoring of treatment adherence and revisiting treatment plans based on feedback from families and treatment efficacy are also emphasized.

\section{Challenges for collaborative decision-making in pediatric chronic illness}

We recognize that implementing a collaborative decisionmaking approach such as the anticipatory guidance model in pediatric management poses significant challenges. ${ }^{48,49}$ For example, the compressed time-frame of followup visits in pediatric chronic illness care is clearly an obstacle. In addition, decision-making in pediatrics can be complicated by the involvement of multiple family members, especially if parents are divorced and remarried and grandparents are involved. Moreover, the content of chronic illness followup visits generally focuses on a review of progress and symptoms initiated by providers with minimal elicitation of questions from parents and children about their experiences in management of a chronic condition, and discussion of treatment-related decisions. Some parents may feel that they have not had an opportunity to make any significant treatment decisions, particularly if the child was very ill at the time of diagnosis and/or has a life-threatening illness. For this reason, providers also need to inquire about the treatment-related decisions that the child and family have made since the last visit. As families gain increased confidence in managing the child's illness, they may become increasingly willing to participate actively in treatment decisions. For others, the potential for making a "bad" treatment decision can be overwhelming. For example, if a child has previously experienced a rare treatment-related complication, parents may experience guilt, anticipate negative outcomes, and hesitate to take an active role in decisions about treatment.

In light of all of these factors, additional training and support for providers will be needed to improve the quality of provider-family communication and collaborative decisionmaking. For example, some hospitals have developed training for providers to facilitate reflective listening concerning family concerns and routine use of specific tools to facilitate provider-family dialogue. ${ }^{50}$ Strategies of anticipatory guidance to promote collaborative decision-making will need to be tailored to child and family preference, ability, and skill level. Even if providers encourage parents to initiate decision-making and communicate their concerns about their child's medical treatment, some parents may not feel comfortable expressing opinions that are contrary to medical advice. Moreover, parents' desire for information about their child's condition does not always correspond to an equal desire for involvement in or responsibility for decision-making. Although many families may want to be informed about treatment options, they may still prefer to rely on their child's' physician to make the final decision.

Gambone and Reiter ${ }^{51}$ have developed a format for presenting recommendations and costs and benefits of treatment that can facilitate family engagement in dialogue about treatment-related decisions. For example, informing the child and parents that many families find the treatment of chronic condition to be burdensome, and that few children complete all of their prescribed treatments will help to facilitate discussion of decision-making relating to treatment adherence. Informing children and parents that it is very important to work together to discuss barriers to adherence that are experienced and revisit ongoing decisions about medical treatment will also facilitate dialogue. Initiating such dialogue during medical visits can facilitate discussion between children and parents who may have talked very little about medical treatment options. Such provider-supported family conversations can provide a unique opportunity for children and parents to share their varying perspectives and preferences in a setting where information can be clarified, questions answered, and effective communication modeled. Finally, open-ended inquiry about family's routines (eg, "Tell me what a typical day is like for you") and treatment decisions eg, "When did you last take your medication?" or "How was it that you decided to take your medication?" can also promote increased provider-family dialogue concerning adherence and decision-making about medical treatment.

\section{Research directions}

One of the important future needs involves research on collaborative decision-making and treatment adherence in the management of pediatric chronic illness. There are two priority areas. The first is descriptive research that characterizes communication and decision-making processes that occur among providers, parents, and children in the management of pediatric chronic illness. Most available data concerning collaborative decision-making in pediatric chronic illness are based on self-reports gathered from individual interviews or focus groups of parents and adolescents. Although these 
data provide important information concerning parent and child perspectives on chronic illness management, direct observation of communication and collaboration is critical to understand collaborative decision-making in pediatric chronic illness care and its relationship to treatment adherence. Methods of observation and coding systems that have been applied to provider-family communication with a range of populations and clinical contexts can be applied to the study of decision-making. ${ }^{52-54}$ Data concerning pediatric providers' perspectives and preferences concerning collaborative decision-making and treatment adherence are also needed. ${ }^{54}$ In addition, research is needed to describe developmental influences on the role of children and adolescents and young adults in clinically relevant decisions concerning ongoing management of chronic pediatric conditions. ${ }^{16}$

The second priority area of research concerns evaluation of the impact of interventions that are designed to enhance collaborative decision-making on provider-family communication, pediatric chronic illness management, and treatment adherence. Although the self-management model has been shown to have a positive impact on the care of adults with chronic illness, ${ }^{12-14}$ to our knowledge no one has evaluated the impact of collaborative decision-making on the health outcomes of children with chronic health conditions. We hypothesize that enhancing collaborative decisionmaking would improve the quality of provider-family communication and problem-solving concerning pediatric chronic illness management, child and family satisfaction with their care, adherence to medical treatment, and health outcomes. Quality improvement research methods that monitor the process of chronic illness management that have been used with adults with chronic conditions can be applied to children with chronic conditions and their families. ${ }^{40,47} \mathrm{We}$ invite researchers and practitioners to provide additional data and insights concerning collaborative decision-making in the management of pediatric chronic illness.

\section{Disclosures}

The authors report no conflicts of interest in this work.

\section{References}

1. World Health Organization: WHO library cataloging-in-publication data. Adherence to Long-term Therapies: Evidence for Action. Geneva, Switzerland: World Health Organization; 2003.

2. Osterberg L, Blaschke T. Adherence to medication. $N$ Engl J Med. 2005;353(5):487-497.

3. Drotar D. Promoting Adherence to Treatment in Childhood Chronic Illnesses: Concepts, Methods, and Interventions. Mahwah, NJ: Lawrence Erlbaum Associates; 2000.
4. Rapoff MA. Adherence to Pediatric Medical Regimens. New York, NY: Kluwer Academic/Plenum Publishers; 1999.

5. DiMatteo MR, Giordani PJ, Lepper HS, Croghan TW. Patient adherence and medical treatment outcomes: A meta-analysis. Med Care. 2002;40(9):794-811.

6. Simpson SH, Eurich DT, Majumdar SR, et al. A meta-analysis of the association between adherence to drug therapy and mortality. BMJ. 2006;333(7557):15.

7. Drotar D, Bonner MS. Influences on adherence to pediatric asthma treatment: A review of correlates and predictors. J Dev Behav Pediatr. 2009;30:574-582.

8. Haskard Zolnierek KB, Dimatteo MR. Physician communication and patient adherence to treatment: A meta-analysis. Med Care. 2009;47:826-834.

9. DiMatteo MR. Practitioner-family-patient communication in pediatric adherence: Implications for research and clinical practice. In: Drotar D, editor. Promoting Adherence to Treatment in Medical Treatment in Chronic Illness: Concepts, Methods, and Interventions. Mahwah, NJ: Lawrence Erlbaum Associates; 2000. p. 237-258.

10. Bauchner H. Shared decision making in pediatrics. Arch Dis Child. 2001;84(3):246.

11. Charles CA, Whelan T, Gafni A, Willan A, Farrell S. Shared treatment decision making: What does it mean to physicians? J Clin Oncol. 2003;21(5):932-936.

12. Greenfield S, Kaplan SH, Ware JE Jr, Yano EM, Frank HJ. Patients' participation in medical care: Effects on blood sugar control and quality of life in diabetes. J Gen Intern Med. 1988;3(5):448-457.

13. Lorig KR, Sobel DS, Stewart AL, et al. Evidence suggesting that a chronic disease self-management program can improve health status while reducing hospitalization: a randomized trial. Med Care. 1999;37(1):5-14.

14. Lorig KR, Ritter P, Stewart AL, et al. Chronic disease self-management program: 2-year health status and health care utilization outcomes. Med Care. 2001;39(11):1217-1223.

15. Butz AM, Walker JM, Pulsifer M, Winkelstein M. Shared decision making in school age children with asthma. Pediatr Nurs. 2007;33(2):111-116.

16. Miller VA. Parent-child collaborative decision making for the management of chronic illness: A qualitative analysis. Fam Syst Health. 2009;27(3):249-266.

17. Bauman LJ. A patient-centered approach to adherence: Risks for nonadherence. In: Drotar D, editor. Promoting Adherence to Medical Treatments in Chronic Childhood Illness: Concepts, Methods, and Interventions. Mahwah, NJ: Lawrence Erlbaum Associates; 2000. p. 71-94.

18. Say RE, Thomson R. The importance of patient preferences in treatment decisions - challenges for doctors. BMJ. 2003;327(7414): 542-545.

19. Martin LR, Williams SL, Haskard KB, Dimatteo MR. The challenge of patient adherence. Ther Clin Risk Manag. 2005;1(3):189-199.

20. Logan D, Zelikovsky N, Labay L, Spergel J. The Illness Management Survey: Identifying adolescents' perceptions of barriers to adherence. J Pediatr Psychol. 2003;28(6):383-392.

21. Loonen HJ, Derkx BH, Griffiths AM. Pediatricians overestimate importance of physical symptoms upon children's health concerns. Med Care. 2002;40(10):996-1001.

22. Kyngas H, Rissanen M. Support as a crucial predictor of good compliance of adolescents with a chronic disease. J Clin Nurs. 2001;10(6): 767-774.

23. Clark NM, Cabana MD, Nan B, et al. The clinician-patient partnership paradigm: outcomes associated with physician communication behavior. Clin Pediatr (Phila). 2008;47(1):49-57.

24. Pound P, Britten N, Morgan M, et al. Resisting medicines: A synthesis of qualitative studies of medicine taking. Soc Sci Med. 2005;61(1): 133-155.

25. Graves MM, Adams CD, Bender JA, Simon S, Portnoy AJ. Volitional nonadherence in pediatric asthma: Parental report of motivating factors. Curr Allergy Asthma Rep. 2007;7(6):427-432. 
26. Adams CD, Dreyer ML, Dinakar C, Portnoy JM. Pediatric asthma: A look at adherence from the patient and family perspective. Curr Allergy Asthma Rep. 2004;4(6):425-432.

27. Leslie LK, Plemmons D, Monn AR, Palinkas LA. Investigating ADHD treatment trajectories: Listening to families' stories about medication use. J Dev Behav Pediatr. 2007;28(3):179-188.

28. Brinkman WB, Sherman SN, Zmitrovich AR, et al. Parental angst making and revisiting decisions about treatment of attention-deficit/ hyperactivity disorder. Pediatrics. 2009;124(2):580-589.

29. Bokhour BG, Cohn ES, Cortes DE, et al. Patterns of concordance and non-concordance with clinician recommendations and parents' explanatory models in children with asthma. Patient Educ Couns. 2008;70(3):376-385.

30. La Greca AM, Mackey ER. Adherence to pediatric regimens. In: Roberts MCS, editor. Handbook of Pediatric Psychology. 4th ed. New York, NY: Guilford Press; 2009. p. 130-152.

31. Ernst E. Prevalence of complementary/alternative medicine for children: A systematic review. Eur J Pediatr. 1999;158(1):7-11.

32. Ang JY, Ray-Mazumder S, Nachman SA, Rongkavilit C, Asmar BI, Ren CL. Use of complementary and alternative medicine by parents of children with HIV infection and asthma and well children. South Med J. 2005;98(9):869-875.

33. Ong LM, de Haes JC, Hoos AM, Lammes FB. Doctor-patient communication: A review of the literature. Soc Sci Med. 1995;40(7): 903-918.

34. McCabe MA. Involving children and adolescents in medical decision making: Developmental and clinical considerations. J Pediatr Psychol. 1996;21(4):505-516.

35. Buford TA. Transfer of asthma management responsibility from parents to their school-age children. J Pediatr Nurs. 2004;19(1):3-12.

36. Klostermann BK, Slap GB, Nebrig DM, Tivorsak TL, Britto MT. Earning trust and losing it: Adolescents' views on trusting physicians. J Fam Pract. 2005;54(8):679-687.

37. Dunsmore J, Quine S. Information, support, and decision-making needs and preferences of adolescents with cancer: Implications for health professionals. J Psychosoc Oncol. 1995;13:39-56.

38. Spinetta JJ, Masera G, Eden T, et al. Refusal, non-compliance, and abandonment of treatment in children and adolescents with cancer: A report of the SIOP Working Committee on Psychosocial Issues in Pediatric Oncology. Med Pediatr Oncol. 2002;38(2):114-117.

39. Reiss JG, Gibson RW, Walker LR. Health care transition: Youth, family, and provider perspectives. Pediatrics. 2005;115(1):112-120.
40. Annunziato RA, Emre S, Shneider BL, et al. Transitioning health care responsibility from caregivers to patient: A pilot study aiming to facilitate medication adherence during this process. Pediatr Transplant. 2008;12(3):309-315.

41. Weissberg-Benchell J, Wolpert H, Anderson BJ. Transitioning from pediatric to adult care: A new approach to the post-adolescent young person with type 1 diabetes. Diabetes Care. 2007;30(10):2441-2446.

42. Bissell P, May CR, Noyce PR. From compliance to concordance: Barriers to accomplishing a re-framed model of health care interactions. Soc Sci Med. 2004;58(4):851-862.

43. Hobden A. Concordance: A widely used term, but what does it mean? Br J Community Nurs. 2006;11(6):257-260.

44. Horne R. Compliance, adherence, and concordance: Implications for asthma treatment. Chest. 2006;130(1 Suppl):65S-72S.

45. Glasgow RE, Goldstein MG, Ockene JK, Pronk NP. Translating what we have learned into practice. Principles and hypotheses for interventions addressing multiple behaviors in primary care. Am J Prev Med. 2004;27(2 Suppl):88-101.

46. Lorig KR, Holman H. Self-management education: History, definition, outcomes, and mechanisms. Ann Behav Med. 2003;26(1):1-7.

47. Pai ALH, Drotar D. Medication adherence in pediatric oncology. In: Kazak AE, Kupst MJ, Pao M, Patenaude AF, Wiener L, editors. Quick Reference for Oncology Clinicians: The Psychiatric and Psychological Dimensions of Cancer Symptom Management. Charlottesville, VA: IPOS Press; 2009. p. 90-96.

48. Wagner EH, Glasgow RE, Davis C, et al. Quality improvement in chronic illness care: A collaborative approach. Jt Comm J Qual Improv. $2001 \mathrm{Feb} ; 27(2): 63-80$.

49. McNutt RA. Shared medical decision making: Problems, process, progress. JAMA. 2004;292(20):2516-2518.

50. Cincinnati Children's Hospital Medical Center. CCHMC Self Management Guideline Implementation.Cincinnati, OH:CCHMC; 2009.

51. Gambone JC, Reiter RC. Quality improvement in health care. Curr Probl Obstet Gynecol Fertil. 1991;14:151-175.

52. Roter DL, Hall JA. Physicians' interviewing styles and medical information obtained from patients. J Gen Intern Med. 1987;2:325-329.

53. Crossley J, Eiser C, Davies HA. Children and their parents assessing the doctor-patient interaction: A rating system for doctors' communication skills. Med Educ. 2005;39(8):820-828.

54. Jahng KH, Martin LR, Golin CE, DiMatteo MR. Preferences for medical collaboration: patient-physician congruence and patient outcomes. Patient Educ Couns. 2005;57(3):308-314.
Patient Intelligence

\section{Publish your work in this journal}

Patient Intelligence is an international, peer-reviewed, open access journal that characterizes and measures the central role of patient behavior and intention in optimizing healthcare management in all areas of disease and complaint types. An improved understanding of patient intelligence coupled with predictive analysis helps an organization contribute more effectively to achieving better outcomes.

\section{Dovepress}

The journal is characterized by the rapid reporting of reviews, original research, methodologies, analytics, modeling, clinical studies and patient surveys across all disease areas. The manuscript management system is completely online and includes a very quick and fair peer-review system. Visit http://www.dovepress.com/ testimonials.php to read real quotes from published authors. 